\title{
Reply:
}

\section{Progression of retinal artery occlusion in Susac syndrome}

\author{
Progressão de oclusão da artéria da retina na síndrome de Susac
}

MÁrio Luiz Ribeiro Monteiro ${ }^{1}$

We thank Drs. Yildirim, Kar and Kaya for their interest regarding our paper ${ }^{(1)}$ reporting the uncommon occurrence of central retinal artery occlusion (CRAO) in Susac syndrome (SS) and for re-emphasizing the point that we have made in the article that SS should be kept in mind even when a patient presents with CRAO in one eye only. However we would like to point out that their statement "retinal artery occlusion in a pathognomonic sign of SS" should be better explained since branch retinal artery occlusions (BRAO) are is in fact the most important diagnostic sign of the syndrome. CRAO is absolutely rare in the condition and therefore it is important to remind that other more common causes such as emboli are excluded before considering SS in such cases. Yildirim, Kar and Kaya also pointed out that progression from one eye to the other should be considered a sign of the disease and quote several previous articles that have described it. Although 
we understand their point, it is also important to consider that the most common presentation of SS is that of BRAO present in both eyes at first examination and that BRAO can also be present in only one of the eyes. In fact, one of the two original cases (case 1) described by Susac, Hardman and Selhorst ${ }^{(2)}$ had BRAO in only one eye despite having an advanced disease. However, when we added the four subsequent cases that allowed a full characterization of the syndrome $e^{(3,4)}$ BRAO was present in both eyes in five of the six cases. On the other hand, we completely agree with Drs. Yildririm, Kar and Kaya that very early in the condition the disease may in fact start in one of the eyes and when progression from one eye to the other occurs it certainly favors the diagnosis of SS as opposed to other more common causes of (unilateral) retinal artery occlusion. We also agree that early diagnosis and treatment is important for preventing further visual and hearing loss as well as worsening of encephalopathy in this unique condition.

\section{REFERENCES}

1. Apostolos-Pereira SL dos, Kara-Jose LB, Marchiori PE, Monteiro ML. Unilateral central retinal artery occlusion as the sole presenting sign of Susac syndrome in a young man: case report. Arq Bras Oftalmol. 2013:76(3):192-4

2. Susac JO, Hardman JM, Selhorst JB. Microangiopathy of the brain and retina. Neurology. 1979;29(3):313-6.

3. Coppeto JR, Currie JN, Monteiro ML, Lessell S. A syndrome of arterial-occlusive retinopathy and encephalopathy. Am J Ophthalmol. 1984;98(2):189-202.

4. Monteiro ML, Swanson RA, Coppeto JR, Cuneo RA, DeArmond SJ, Prusiner SB. A microangiopathic syndrome of encephalopathy, hearing loss, and retinal arteriolar occlusions. Neurology. 1985;35(8):1113-21.

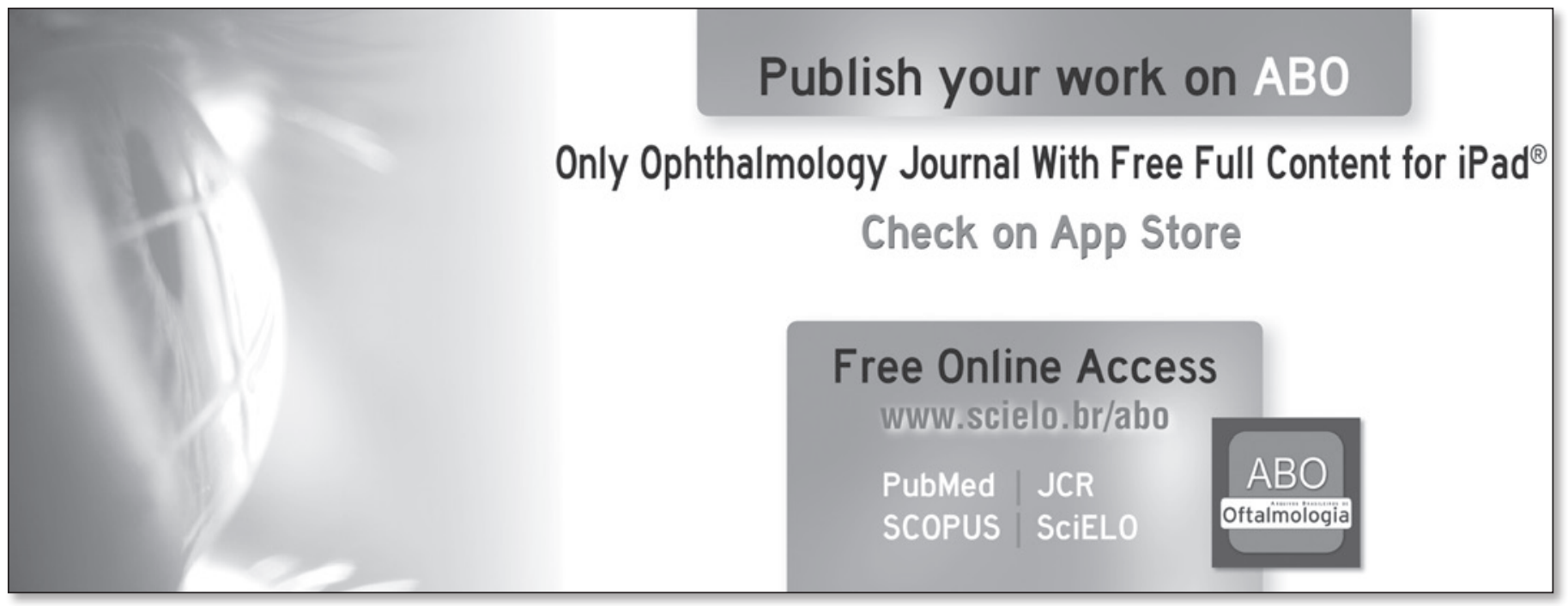

